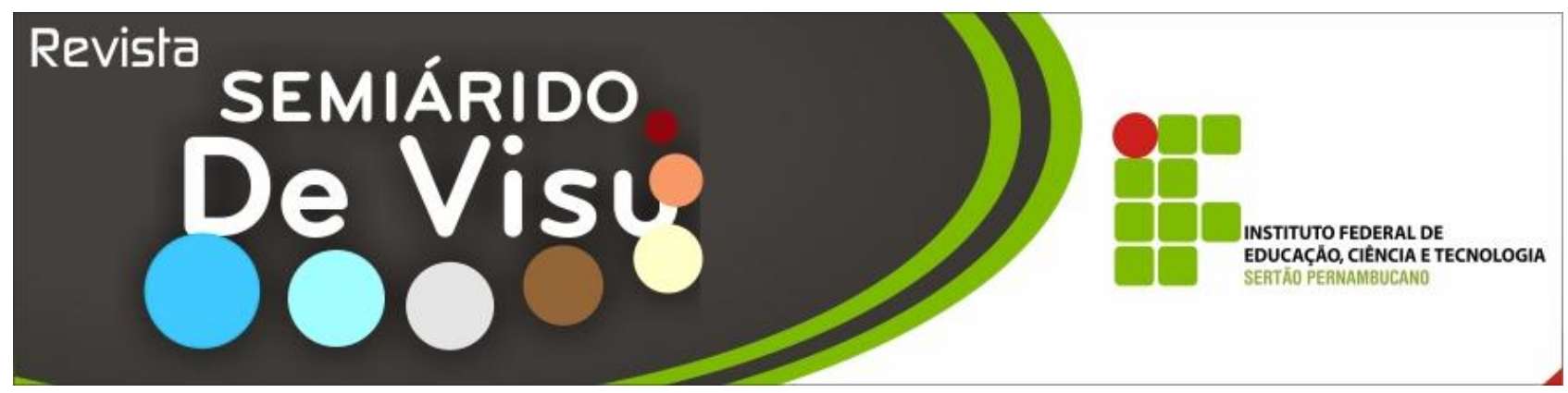

\title{
Percepção da identidade étnico-racial do ensino médio integrado no IF Sertão- PE, Campus Petrolina
}

\author{
Edivania Granja da Silva Oliveira ${ }^{1}$, Amanda de Souza Albuquerque ${ }^{1}$ \\ ${ }^{1}$ Instituto Federal de Educação, Ciência e Tecnologia do Sertão de Pernambucano - IF SERTÃO-PE Petrolina, PE. \\ E-mail: edivania.granja@ifsertao-pe.edu, amanda7818@gmail.com
}

\begin{abstract}
RESUMO: Este artigo pretende demonstrar dados coletados e análises sobre o perfil étnico-racial e a percepção sobre questões étnico-raciais da comunidade acadêmica do IF SERTÃO PE CAMPUS PETROLINA, objetivo do Projeto PIBIC Júnior, desenvolvido de maio de 2011 a janeiro de 2012, que teve como base a Lei $\mathrm{n}^{\circ}$ 11.645/08, visando compreender o ambiente escolar como espaço de pluralidade e identidade cultural, componentes fundamentais da nossa sociedade. Por fim, o diagnóstico efetuado sobre as questões étnico-raciais na percepção dos alunos do Ensino Médio Integrado sobre identidade étnico-racial e o ambiente escolar exigirá ações metodológicas na área de ensino e de aprendizagem no Campus Petrolina a fim de aprofundar maiores conhecimentos sobre a temática para ampliar a convivência com a diversidade e pluralidade cultural da sociedade brasileira.
\end{abstract}

Palavras-chave: educação, diversidade, pluralidade cultural.

\section{Perception of ethnic-racial identity of integrated School IF Sertão-PE, Campus Petrolina, PE, Brazil}

\begin{abstract}
This articleseeks to showthe collected dataand analysis on theethnic and racialprofileandperception ofethnic andracialissuesin the academic communityof theIFSERTÃOPETROLINACAMPUSPE, JuniorPIBICobjective of the Project, developed from May2011to January2012, whichwasbased onLaw No.11.645/08, to understand the school environmentas a spaceof plurality andcultural identity, key componentsof our society. Finally, the diagnosis madeon ethnic-racial perceptions ofhigh school studentsonIntegratedethno-racial and school environmentwill requiremethodologicalactionsin the area ofteaching and learningon campusPetrolinain order to developmore knowledgeon the subjectto increasethe familiarity with theculturaldiversity and pluralityof Brazilian society.
\end{abstract}

Keywords: Education, identity, diversity and cultural plurality 
Edivania Granja da Silva Oliveira et al.

\section{Introdução}

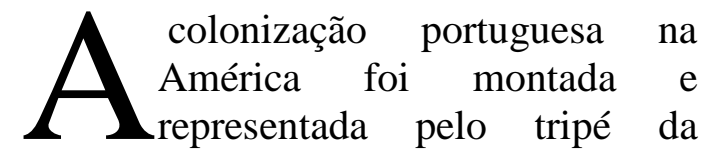
monocultura, do latifúndio e da escravidão. (RANGEL, 1993).

Nesse sentido, deve-se pontuar que o processo de formação histórica vivenciado por índios, negros e outros povos na sociedade brasileira é de tratamento diferenciado, como seres inferiores, em função de sua cultura, raça ou condição social, dentro da visão do branco europeu. (CARNEIRO, 2002).

Vale ressaltar que mesmo após a abolição da escravidão no Brasil foi vivenciado a ideia da nova construção da identidade nacional. No início do período republicano o branqueamento da população era fator determinante para a modernização do país, teoria que perdurou até meados da década de 30 do século XX. Em contraposição a esse ideário surge à concepção da democracia racial, na qual a boa convivência entre brancos $\mathrm{e}$ negros formou o elemento mestiço. E somente a partir das últimas décadas do século $\mathrm{XX}$, há uma luta mais efetiva para demonstrar que as desigualdades sociais tem relação intrínseca com as desigualdades raciais.

Assim, o cenário atual de um país republicano e democrático perdura o desafio de enfrentamento das desigualdades sociais e raciais, no qual pobres e afrodescendentes transformam-se em sujeitos políticos, mas ainda carecendo de inserção social para legitimar a Nação brasileira. (JACCOUD, 2008).

A compreensão neste trabalho é do papel da educação como produtora e construtora de processos formativos, geradora de oportunidades e instrumentos eficazes de ascensão social. Dessa forma, a educação é um dos caminhos para ampliar as oportunidades dos excluídos ou menos favorecidos da sociedade brasileira.

Com o intuito de combater as desigualdades históricas e oportunizar maior participação dos afrodescendentes foi instituída a Lei no. 10.639/03 que trata da obrigatoriedade do estudo da História da África e da cultura afro-brasileira e das Diretrizes curriculares nacionais para as relações étnicoraciais das temáticas em destaque (BRASIL, 2003). A Lei 11.645/08 foi instituída para incluir o estudo da cultura indígena. As temáticas em questão devem ser ministradas no âmbito de todo o currículo escolar, principalmente nas áreas de educação artística, de literatura e de história. (BRASIL, 2008).

Os Parâmetros Curriculares Nacionais definem a pluralidade cultural como um dos temas transversais, devendo ser tratado no currículo escolar a fim de contribuir para o respeito com as diversas culturas brasileiras, compreendendo a origem de formação do povo brasileiro a partir do combate a concepção de uniformidade cultural para afirmação da identidade nacional. (BRASIL, 1998).

A aplicabilidade dessa Lei no âmbito escolar deve ter $\mathrm{o}$ intuito de propiciar discussões sobre pluralidade cultural, identidade, desigualdade racial através do reconhecimento e da valorização da diversidade cultural da nossa sociedade, considerando às questões étnico-raciais para afirmação identitária.

A identidade é definida como componente histórico e não biológico, de acordo com Hall (2003, p. 13), "Dentro de nós há identidades contraditórias, empurrando em diferentes direções, de tal modo que nossas identificações estão sendo continuadamente deslocadas".

Pensar sobre a construção da identidade do indivíduo é a partir da percepção de reconhecimento do outro, pois há "um complexo relacional que liga o sujeito a um quadro contínuo de referências, constituído pela inserção de sua história individual com a do grupo onde vive". Sodré (1999, p. 34).

A construção de identidade cultural pode ser também com o sentido atribuído por Castell (1999), que trata sobre o processo de construção identitária a partir de um determinado atributo cultural ou num conjunto de elementos culturais que se inter-relacionam criando novos significados, favorecendo a multiplicidade e pluralidade de identidades, num processo de contradição e de tensão tanto 
Edivania Granja da Silva Oliveira et al.

em relação à própria representação ou na ação social.

Por isso, a compreensão da pluralidade e da diversidade cultural são questões pertinentes para o combate à discriminação, ao reconhecimento e a afirmação das identidades étnico-raciais do povo brasileiro.

\section{Material e métodos}

A percepção da pluralidade e diversidade cultural são fatores essenciais para o combate à discriminação e o reconhecimento das identidades étnico-raciais do povo brasileiro, intenção do Projeto de Pesquisa PIBIC Júnior - Perfil Étnico-racial da Comunidade Acadêmica IF SERTÃO PE Campus Petrolina através do diagnostico do perfil étnico-racial da comunidade acadêmica do Campus Petrolina, com base na Lei $\mathrm{n}^{\circ}$ $11.645 / 08$.

O projeto pretendeu caracterizar o perfil étnico-racial dos alunos do Ensino Médio Integrado do Campus Petrolina com a adoção do critério de identidade através da autodeclaração, bem como analisar as concepções e expressões acerca das discriminações e preconceitos sofridos ou relatados pelos entrevistados.

Para o desenvolvimento do Projeto foi efetuado levantamento bibliográfico e pesquisa de campo, discussões e análise pertinentes às questões da cultura afro-brasileira e indígena, de acordo com os Parâmetros Curriculares Nacionais e de estudo da História do Brasil.

As Diretrizes destacam com relação ao combate ao racismo para as relações étnicoraciais que,

(...) Entre os negros, poderão oferecer conhecimentos e segurança para orgulharem-se da sua origem africana; para os brancos poderão permitir que identifiquem as influências, a contribuição, à participação e a importância da história e da cultura dos negros no seu jeito de ser, viver, de se relacionar com as outras pessoas, notadamente as negras. (BRASIL, 2004, p.16).

Por isso, o projeto pretendeu favorecer no espaço escolar a afirmação e valorização da identidade étnico-racial da comunidade educativa, a fim de perceber a diversidade cultural do povo brasileiro.

Para tanto, os procedimentos metodológicos utilizados teve como parâmetro a pesquisa qualitativa, na compreensão que a pesquisa de campo deve compreender o ambiente natural como fonte direta de dados, tendo como principal instrumento $o$ pesquisador, numa relação de interação entre pesquisa e pesquisador no ambiente investigado para firmar-se como pesquisa qualitativa. (LUDKE \& ANDRÉ, 1986).

Dessa forma foi elaborado questionário, utilizando a técnica de abordagem do trabalho de campo na busca de compreender e ampliar a visão a respeito do tema proposto através da análise das questões dos alunos do Ensino Médio Integrado do IF SERTÃO-PE - Campus Petrolina, a fim de perceber o contexto teórico e prático, as possibilidades de reflexão da prática do processo educacional a fim de garantir o respeito à diversidade e a pluralidade cultural no universo escolar.

O questionário elaborado contém duas partes, sendo a primeira parte referente à classificação de Sexo (masculino ou feminino), Idade, Nome do Aluno, Modalidade e Série do Curso. E a segunda parte do questionário envolveu as categorias de Identificação Étnica através da autodeclaração (pergunta aberta) e de acordo com o IBGE (pergunta fechada), Representação dos negros em programas midiáticos (pergunta fechada e aberta), Lei Contra Discriminação Racial (pergunta fechada e aberta), Inclusão do estudo da África e da Cultura Afro-brasileira e Indígena nos conteúdos escolares (pergunta fechada), Lei de Cotas (pergunta fechada e aberta), Convivência entre grupos étnicos (pergunta fechada), Projeto pedagógico sobre Cultura Afrobrasileira e Indígena no Campus Petrolina (pergunta fechada) e Existência de Racismo no Brasil (pergunta fechada e aberta).

O cenário da pesquisa foi o espaço escolar do Campus Petrolina e a coleta dos dados foi realizada através de entrevistas com discentes, utilizando um questionário semiestruturado com perguntas fechadas (de 
Edivania Granja da Silva Oliveira et al.

múltipla escolha) e também abertas (de estimação ou avaliação).

Com o intuito de envolver os alunos para participar das entrevistas foi realizado um Seminário, no qual foi apresentado o projeto com ênfase nos conceitos de Identidade e Etnia, no processo histórico de formação étnica da sociedade brasileira, as diretrizes educacionais da Lei $10.639 / 03$ e $11.645 / 08$ e a importância do censo étnico-racial no espaço escolar.

A aplicação dos questionários deu-se a partir de agendamento prévio com professores efetuado pela Técnica Educacional da Escola, que colaborou com a organização da aplicação dos questionários.

O tempo de duração que os alunos usaram para responderem ao questionário foi em média de 40 minutos, portanto foi utilizada em média uma hora/aula em cada turma para realização da pesquisa de campo.
O questionário foi aplicado durante os meses de maio a agosto de 2011 em todos os cursos e séries do Ensino Médio Integrado.

Vale salientar que durante a aplicação dos questionários em todas as turmas, os alunos fizeram questionamentos sobre a finalidade do trabalho, além de provocar debates e discussões sobre as questões propostas, com maior ênfase na questão que trata sobre as cotas de acesso à universidade.

\section{Resultados e discussão}

Os dados extraídos com relação ao gênero, 142 alunos pertencem ao sexo feminino e 162 são do sexo masculino.

Em relação à faixa etária constatou-se que a maioria dos alunos tinha 16 anos de idade, de acordo com o gráfico abaixo:

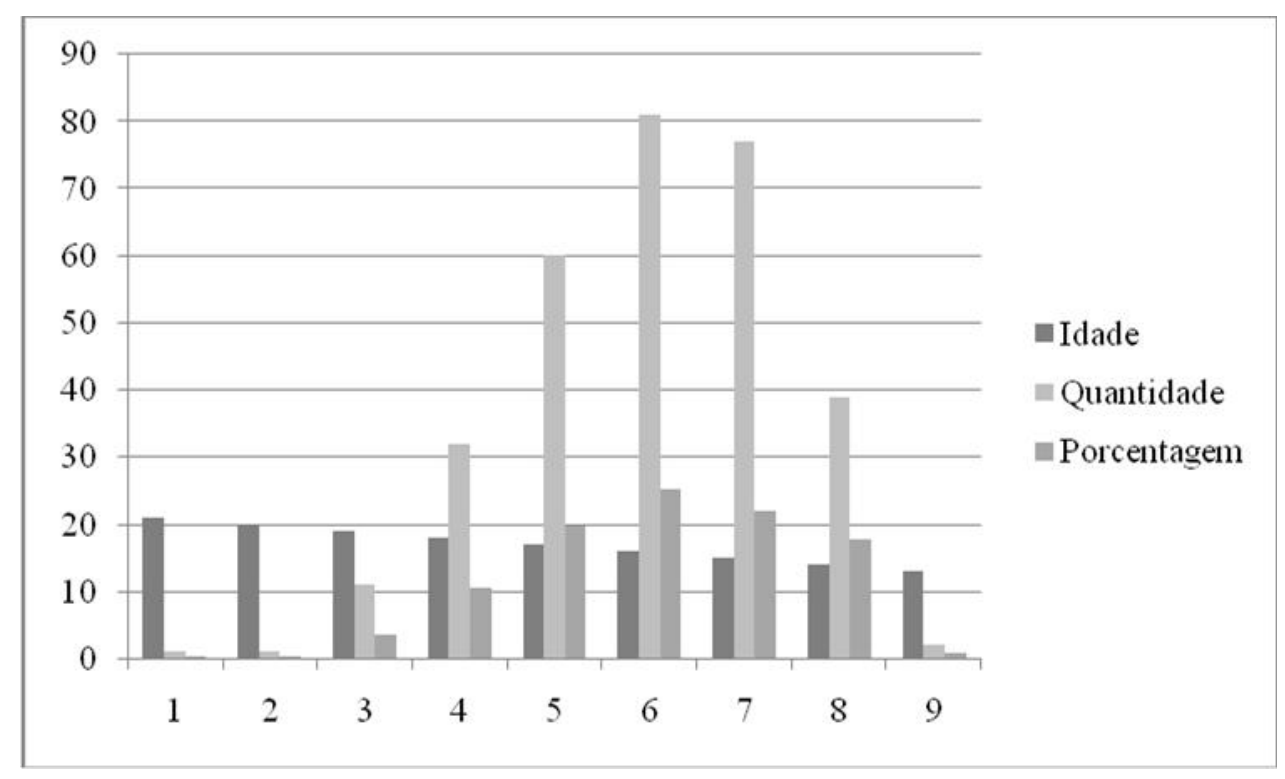

\section{GRÁFICO 1 - Idade dos alunos entrevistados}

O quantitativo de alunos regularmente matriculados no Ensino Médio Integrado em 2011 era de 372 discentes, dados coletados no Controle Acadêmico do Campus Petrolina. Foram entrevistados 304 alunos, portanto 68 alunos não participaram da pesquisa, por não estarem na sala de aula no momento da aplicação dos questionários, conforme indicado na Tabela abaixo: 
Edivania Granja da Silva Oliveira et al.

TABELA 1 - Demonstrativo de Alunos Participantes da Pesquisa:

\begin{tabular}{lcc}
\hline \multicolumn{1}{c}{ CATEGORIA } & QUANTIDADE & RESULTADO (\%) \\
\hline Alunos Matriculados & 372 & 100 \\
Alunos Entrevistados & 304 & 81,72 \\
Alunos não Entrevistados & 68 & 18,28 \\
\hline
\end{tabular}

Os alunos que responderam ao questionário de acordo com a modalidade de ensino e a série do curso foi o seguinte:

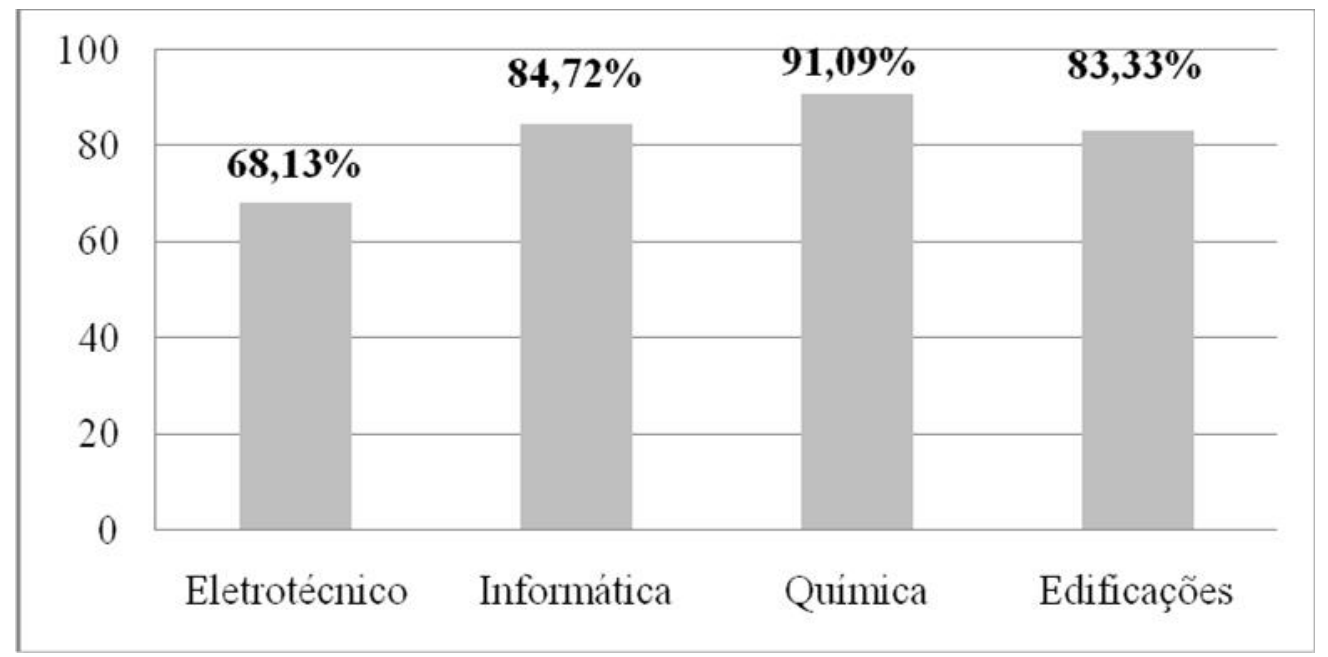

\section{Gráfico 2 - Demonstrativo por Curso de Alunos Participantes da Pesquisa}

Nos itens relacionados à autodeclaração foram questionados como os entrevistados se definem em relação à identidade étnico-racial (pergunta aberta), tendo os seguintes resultados:

\section{TABELA 2 - Quantitativo de Identificação Étnico-Racial:}

\section{IDENTIFICAÇÃO ÉTNICO-RACIAL}

\section{Moreno Claro}

Moreno

Moreno Escuro

Pardo

Branco

Negro

Mestiço

Mulato

Galego

Amarelo

Não declarou

\section{QUANTIDADE}

44

41

09

78

71

22

14

08

05

04

08
Destaca-se que o maior quantitativo de alunos do universo pesquisado foi em relação às nuances de moreno, moreno claro e moreno escuro, totalizando 94 alunos nessas categorias.
No item de acordo com a categoria de cor utilizada pelo IBGE (pergunta fechada), o quantitativo maior é de alunos, 174 declararamse pardos, de acordo com a tabela abaixo: 
Edivania Granja da Silva Oliveira et al.

TABELA 3 - Categorias de Cor - IBGE

\begin{tabular}{cc}
\hline COR IBGE & QUANTIDADE \\
\hline PARDA & 174 \\
BRANCA & 71 \\
PRETA & 35 \\
AMARELA & 23 \\
INDÍGENA & 0 \\
NÃO DECLAROU & 01 \\
\hline
\end{tabular}

Pode-se analisar que a categoria parda, de acordo com o IBGE foi utilizada pelos alunos que se autodeclararam com as nuances de morenos e de pardos no item anterior.

A Cor Preta em relação à categoria do IBGE foi de 35 declarações e na Identificação Étnico-Racial foi de 22 alunos, pressupõe que a diferença possa fazer parte dos tipos de Cor Mestiço ou Mulato, colocados na autodeclaração de Identificação Étnico-Racial.

Em relação à categoria Cor Amarela houve significativa diferença entre os itens questionados, pois no item de acordo com o IBGE 23 alunos autodeclaram de Cor Amarela, enquanto que na definição Étnica somente 04 alunos se autodeclaram. Nesse caso, acredita-se que os alunos que autodeclaram como Galegos, Mestiços, ou não Declararam a cor podem ter se autodeclarados Amarelos na questão fechada, de acordo com o IBGE.

Destaca-se que a cor Branca permaneceu a mesma entre os dois itens e a Cor Indígena não foi citada em nenhuma das duas situações.

Vale destacar a Obra "O Escravismo no Brasil", de Luna e Klein (2010), que fazem uma abordagem sobre o período de transição da escravidão para a liberdade analisando a imagem negativa da cor negra e consequentemente da identidade negra e da opção do "embranquiçamento",

[...] o que distinguia o Brasil não era tanto a ausência de preconceito, mas as sutis diferenciações que o preconceito criava. A classe era um determinante de posição tão poderoso que em geral os atributos de classe influenciavam a definição de cor, independentemente de características fenotípicas do indivíduo. Muitos advogados negros eram definidos como mulatos, e mulatos, como brancos [...]. (LUNA; KLEIN, 2010, p. 339).

Assim, pode-se transpor essa análise para o universo pesquisado, indicando a necessidade de aprofundar as discussões que envolvem identidade étnico-racial, pois há pouca identificação com a cultura negra e ausência de identificação com a cultura indígena por parte dos entrevistados, suscitando questionamentos sobre a presença no imaginário dos alunos entrevistados da identificação com a cultura dita branca ou algo que fique próximo, como é o caso das nuance dos tipos de morenos apresentados.

A respeito das funções que a maioria dos negros representa em programas midiáticos (novelas, filmes, série, programas humorísticos, etc.), os alunos responderam que: 
Edivania Granja da Silva Oliveira et al.

TABELA 4 - Representações de Funções de Negros em Programas Midiáticos

\begin{tabular}{lc}
\hline \multicolumn{1}{c}{ FUNÇÕES } & QUANTITATIVO \\
\hline Pobre & 191 \\
Favelado & 176 \\
Malandro & 169 \\
Empregado doméstico & 134 \\
Empresário & 20 \\
Intelectual & 13 \\
Rico & 09 \\
Outros & 09 \\
\hline
\end{tabular}

Os participantes da pesquisa concluíram que a maioria dos negros representam papel profissional subalterno ou desclassificados no espaço midiático. Como reforçam Acevedo e Nahara (2008), no artigo "Interpretações sobre os retratos dos afro-descentes na Mídia de Massa",

[...] $\mathrm{Na}$ verdade as pesquisas indicam que os papeis principais pertencem aos brancos. $\mathrm{O}$ papel secundário é operacionalizado por diversos indicadores, como o tempo de exposição da personagem, o enquadramento dela, o nível de atividade, a autonomia dela e a atribuição de nome próprio.Assim, em comparação com os brancos, os afrodescendentes são focalizados bem mais rapidamente e poucas vezes aparecem no centro da página ou da câmera [...] o que sugere dominação e desigualdade entre as personagens apresentadas. (ACEVEDO E NAHARA, 2008, p. 126).

Foi feita pergunta sobre a Lei de Discriminação Racial, 17 alunos não responderam, 03 alunos foram contra a Lei e 157 alunos foram favoráveis a Lei, mas não destacaram os motivos. Enquanto que 127 alunos concordaram com a lei e responderam com as seguintes justificativas:

\section{TABELA 5 - Lei de Discriminação Racial}

\begin{tabular}{lc}
\hline \multicolumn{1}{c}{ JUSTIFICATIVA } & QUANTIDADE \\
\hline Todos são iguais, Respeito e Direitos iguais; & 84 \\
Combate a Discriminação e Racismo & 35 \\
Direito dos Negros e Melhorias Sociais & 08 \\
\hline
\end{tabular}

Ressalta que a justificativa foi feita através de síntese da escrita dos alunos com destaque para palavras-chave ou frases que apareceram nos questionários respondidos.

Constava no questionário uma pergunta objetiva sobre a inclusão da História da África, da Cultura Afro-brasileira e Indígena nos conteúdos escolares como componentes favoráveis à diminuição das desigualdades sociais no Brasil. A maioria, 232 alunos responderam que acreditam que o estudo da temática irá contribuir para a igualdade social brasileira, enquanto que, apenas 69 alunos não concordaram com o questionamento e 03 alunos não responderam a pergunta.

No item sobre Lei de Cotas, os alunos deveriam responder se eram contra ou a favor da lei de cotas. Caso a resposta fosse favorável teriam que marcar quais critérios (pergunta fechada), obtendo as seguintes respostas: 
Edivania Granja da Silva Oliveira et al.

TABELA 6 - Lei de Cotas

\begin{tabular}{lc}
\hline \multicolumn{1}{c}{ CRITÉRIOS } & QUANTIDADE \\
\hline Rede Pública & 101 \\
Negros, Indígena e Rede Pública & 16 \\
Negros & 14 \\
Negros e Rede Pública & 08 \\
Negros e Indígenas & 04 \\
Indígenas & 02 \\
Indígenas e Rede Pública & 01 \\
\hline
\end{tabular}

De forma geral, a maioria dos entrevistados foi favorável às cotas de acesso à universidade, pois 187 alunos concordaram com a Lei de Cotas, enquanto 112 alunos discordaram e 05 alunos não responderam.

Segundo o depoimento da aluna B. L. de F. S., 17 anos, a Lei de Cotas para acesso à Universidade deve ter como critérios Negros e
Indígenas, esclarecendo que "Diante de problemas socioeconômicos é preciso dar oportunidades para quem não as têm voluntariamente".

$\mathrm{Na}$ pergunta feita aos alunos se já haviam presenciado algum tipo ou situação de Discriminação na Escola, foi coletado os seguintes dados:

\section{TABELA 7 - Discriminação no Espaço Escolar}

\begin{tabular}{lc}
\hline \multicolumn{1}{c}{ Respostas } & Quantidade \\
\hline Não responderam a questão & 165 \\
Não & 97 \\
Sim & 42 \\
\hline
\end{tabular}

Alguns alunos que confirmaram já ter presenciado discriminação no espaço escolar descreveram algumas situações, como apelidos de "Preto", "Carvãozinho", "Asfalto queimado", "Nego d'água", "Mutuca Preta", "Nego Preto", “Acarajé Queimado", "Tição", ressaltaram também o uso de xingamentos e piadas.

Ainda nesse item sobre a ausência de respostas e também a negativa sobre discriminação no espaço escolar pode suscitar alguns questionamento, tais como falta de conhecimento sobre conceito de discriminação, atribuição a formas de discriminação como brincadeiras e ainda a ausência de práticas educativas reflexivas sobre a temática.

Os alunos foram questionados (pergunta fechada) sobre a convivência entre os grupos étnicos no espaço escolar do Campus Petrolina, com as opções a serem assinaladas, Muito Boa, Boa, Razoável e Ruim, destacados na Tabela abaixo:

\section{TABELA 8 - Convivência Étnico-Racial}

\begin{tabular}{lcc}
\hline & OPÇÕES & QUANTITATIVO \\
\hline Boa & 137 \\
Muito Boa & 129 \\
Razoável & 36 \\
Ruim & 02 \\
\hline
\end{tabular}

A rede de sociabilidade estabelecida no Campus Petrolina é fator primordial para aprofundar as questões étnico-raciais, pois os alunos percebem o espaço escolar de forma bastante positiva em relação à boa convivência entre seus membros. Mas, alguns alunos destacaram casos que presenciaram ou sofreram discriminação ao longo da vida 
Edivania Granja da Silva Oliveira et al.

escolar, como diz a aluna L. P. de C., 16 anos, "A professora da minha $4^{\mathrm{a}}$ série, chamando o mesmo que estava bagunçando de "nego feio"”. Já a aluna J. C. B., 15 anos relata, "Já aconteceu comigo, por causa da minha cor um menino estava debochando de mim".
Os alunos foram questionados se a escola dispõe de Projeto Pedagógico com a temática da Cultura Afro-brasileira e Indígena, conforme a tabela a seguir:

\section{TABELA 9 - Projeto Pedagógico Cultura Afro-brasileira e Indígena}

\begin{tabular}{cc}
\hline Informação Projeto Escola & QUANTIDADE \\
\hline Não sabem & 184 \\
Conhecem Projeto & 119 \\
Não respondeu & 01 \\
\hline
\end{tabular}

Essa questão deverá ser considerada pela Comissão do Projeto de Cultura Afro e Indígena do Campus Petrolina para redirecionar suas ações na divulgação e no aprofundamento do Projeto em questão, para que os alunos possam melhor perceber a finalidade e a aplicabilidade das temáticas no processo educativo.

A última pergunta do questionário abordou sobre a crença de existência de racismo no Brasil. Caso o aluno respondesse que sim, poderia exemplificar, 291 alunos responderam que existe racismo no Brasil, 08 alunos responderam que não acreditam que exista racismo e 05 alunos não responderam a pergunta.

Os exemplos mais utilizados pelos alunos foram o seguinte:

\section{TABELA 10 - Exemplos de Racismo}

\begin{tabular}{lc}
\hline \multicolumn{1}{c}{ Forma ou Tipo de Racismo } & Quantidade \\
\hline Dificuldade de acesso ao mercado de trabalho & 66 \\
Lei de Cotas de acesso à Universidade & 20 \\
$\begin{array}{l}\text { Negro com frequência é confundido com ladrão e } \\
\text { traficante }\end{array}$ & 15 \\
A TV e o Cinema tratam o negro de forma racista & 06 \\
$\begin{array}{l}\text { Preconceito com a cultura e a religião afro- } \\
\text { brasileira }\end{array}$ & 04 \\
\hline
\end{tabular}

A frequência maior dos exemplos citados pelos alunos foi em relação ao mercado de trabalho e a Lei de Cotas. Nesse caso, foram explicitados que a própria Lei favorece a discriminação, segundo o depoimento do aluno V. S. O. J., 15 anos, "A cota para negros é um exemplo de racismo no Brasil, pois todos temos capacidade de obter conhecimento".

A aluna A. M. R. S. B. O., 16 anos, acredita que o racismo,

É um fator histórico e de difícil mudança na sociedade. A maioria das crianças já cresce com uma ideia racista e é aprofundada pelos meios de comunicação e por outras pessoas. O racismo é algo enraizado, que é preciso cortá-lo da 'raiz' para que futuras gerações possam viver em uma sociedade mais justa.

O racismo está imbricado na sociedade brasileira e para combatê-lo é necessário ampliar ações em diversas instâncias políticas e sociais para efetivamente acabar com as diferenças e desigualdades que os afrobrasileiros, indígenas e outros grupos têm sofrido no processo histórico de formação e consolidação da Nação brasileira. 
Edivania Granja da Silva Oliveira et al.

\section{Conclusões}

Diante dos resultados apresentados, alguns questionamentos podem ser aprofundados em outros estudos para compreender como no universo pesquisado não tenha ocorrência da etnia indígena. Pois, no lançamento do Projeto e durante apresentação de dados coletados para a comunidade educativa no Dia da comemoração da Consciência Negra, os alunos demonstraram a percepção sobre os indígenas semelhante à imagem do índio que constam nos livros didáticos, vivendo na mata, usando adereços e sem roupas.

A problemática sobre as sociedades indígenas brasileira nos livros didáticos apresentada por Gupioni (1995) é que,

[...] Primeiramente pela forma como estas sociedades são tratadas: geralmente pela negação de traços culturais considerados significativos: falta de governo, falta de tecnologia para lidar com os metais, nomadismo, etc. Um segundo modo de operação deste mecanismo de simplificação é a apresentação isolada e descontextualizada de documentos históricos que falam sobre os índios. [...] fatos etnográficos retirados de seu contexto, bem como iconografias da época, são apresentados, criando um quadro de exotismo, de detalhes incompreensíveis, de uma diferença impossível de ser compreendida e, portanto, aceita. É significativo, neste sentido, o fato de muitos livros didáticos usarem, basicamente, informações sobre os índios produzidas nos primeiros séculos da colonização, [...].

Isto pode levar os alunos a concluírem pela não contemporaneidade dos índios, uma vez que estes são quase sempre apresentados no passado e pensados a partir do paradigma evolucionista, [...]. (GUPIONI, 1995, p. 488).

Assim, pode-se apontar que dentre as problemáticas enfrentadas pelos atuais povos indígenas, a invisibilidade seja talvez o maior problema.

Vale destacar que durante a aplicação dos questionários houve maior ocorrência de questionamentos em relação à Lei de Cotas. Pode-se apontar que o assunto é de relevância no universo discentes do Ensino Médio Integrado, devido ao interesse em relação ao acesso à Universidade. Assim, recomenda-se maior discussão sobre a temática no espaço escolar.

A análise dos dados demonstra necessidade de aprofundar estudos sobre conceitos de raça, identidade, negritude, racismo, discriminação e outros a fim de combater formas de preconceitos, de exclusão social, contribuindo para valorização e afirmação da identidade étnico-racial no espaço escolar.

Percebe-se também que o projeto teve destaque na comunidade educativa, como afirma A. M. B., 17 anos, "Muito interessante esse projeto, pois ajuda a todos a declarar sua cor $[\ldots] "$...

Por fim, o diagnóstico efetuado sobre as questões étnico-raciais na percepção dos alunos do Ensino Médio Integrado sobre identidade étnico-racial e o ambiente escolar exigirá ações metodológicas na área de ensino e de aprendizagem no Campus Petrolina a fim de aprofundar conhecimentos sobre a temática para ampliar a convivência com a diversidade e pluralidade cultural da sociedade brasileira, com base na Lei $\mathbf{n}^{0} \mathbf{1 1 . 6 4 5 / 0 8}$.

\section{Agradecimentos}

Agradecemos ao IF SERTÃO PE CAMPUS PETROLINA por apoiar e contribuir com a pesquisa, em especial a servidora Hosana Maria Nogueira Leite, aos docentes e discentes do Ensino Médio Integrado.

\section{Referências}

ACEVEDO, Cláudia Rosa; NAHARA, Jouliana Jordan. Interpretações sobre os retratos dos afro-descentes na Mídia de Massa.RAC, Curitiba, Edição Especial 2008, p. 119-146. Disponível em http://www.scielo.br/pdf/rac/v12nspe/a06v12ns .pdf. Acessado em 15/01/2011.

BRASIL. Lei Federal no. 10.639/ 03. Altera a Lei de Diretrizes e Base da Educação no. 9.394 de 20 de dezembro de 1996. Diário Oficial da 
Edivania Granja da Silva Oliveira et al.

República Federativa do Brasil, Brasília, DF, 09 de janeiro de 2003.

Lei Federal $n^{\circ}$ 11.645/08. Altera a Lei 10.639/03 de 09 de janeiro de 2003. Diário Oficial da República Federativa do Brasil, Brasília, DF, 10 de março de 2008.

- SEF. Parâmetros Curriculares

Nacionais. Brasília: MEC/SEF, 1998.

Ministério da Educação/Secad.

Diretrizes curriculares nacionais para a educação das relações étnico-raciais e para o ensino de história e cultura afro-brasileira e africana na educação básica. 2004.

CARNEIRO, Maria Luiza Tucci. O racismo na História do Brasil: mito e realidade. $8^{\mathrm{a}} \mathrm{ed}$. Ed. Ática, São Paulo, 2002.

CASTELL, Manuel. O Poder da Identidade. São Paulo: Paz e Terra, 1992.

GRUPIONI, Luís Donisete Benzi. Livros didáticos e fontes de informações sobre as sociedades indígenas no Brasil. In: (Org.) SILVA, Aracy Lopes da. e GRUPIONI, Luíz Donisete Benzi. A temática indígena na escola: novos subsídios para professores de $1^{\circ}$ e $2^{\circ}$ graus. Brasília: MEC/MARI/UNESCO, 1995.

HALL, S. A Identidade Cultural na Modernidade. 7 ed. Rio de Janeiro: DP \& A, 2003.

JACCOUD, Luciana. Racismo e República: o debate sobre o branqueamento e a discriminação racial no Brasil. In: Theodoro, Mário (Org.), As políticas públicas e a desigualdade racial no Brasil: 120 anos após a abolição. Brasília: IPEA, 2008.

LUDKE, Menga \& ANDRÉ, Marli, E. D. A. Pesquisa em educação: abordagens qualitativas. São Paulo: EPU, 1986.
LUNA, Francisco Vidal; KLEIN, Herbert S. Escravismo no Brasil. São Paulo: EDUSP, 2010.

RANGEL, I. 500 anos de desenvolvimento da América e do Brasil. Revista Geosul, ano VII, n. 15. Florianópolis, 1993.

SODRÉ, Muniz. Claros e escuros, identidade, povo e mídia no Brasil. Petrópolis: Vozes, 1999. 